\title{
Loss of p73 promotes dissemination of Myc-induced B cell lymphomas in mice
}

\author{
Alice Nemajerova, ${ }^{1}$ Oleksi Petrenko, ${ }^{1}$ Lorenz Trümper, ${ }^{2}$ Gustavo Palacios, ${ }^{1}$ and Ute M. Moll1,3 \\ 1Department of Pathology, Stony Brook University, Stony Brook, New York, USA. 2Department of Hematology and Oncology and \\ ${ }^{3}$ Department of Molecular Oncology, University of Göttingen, Göttingen, Germany.
}

\begin{abstract}
Mice engineered to express c-Myc in B cells (E $\mu$-myc mice) develop lethal lymphomas in which the gene encoding the p53 tumor suppressor is frequently mutated. Whether the p53 homolog p73 also functions as a tumor suppressor in vivo remains controversial. Here we have shown that $\mathrm{p} 73$ loss does not substantially affect disease onset and mortality in $\mathrm{E} \mu$-myc mice. However, it does alter the phenotype of the disease. Specifically, $\mathrm{p} 73$ loss decreased nodal disease and increased widespread extranodal dissemination. We further found that p53 acted as the dominant tumor suppressor during the onset of $E \mu$-myc-driven B cell lymphomagenesis, while p73 modulated tumor dissemination and extranodal growth. Immunophenotyping and expression profiling suggested that $\mathrm{p} 73$ loss allowed increased maturation of malignant $B$ cells and deregulated genes involved in lymphocyte homing and dissemination of human lymphomas. Consistent with this, $\mathrm{p} 73$ expression was frequently downregulated in a large cohort of human mature aggressive $B$ cell lymphomas, and both the incidence and degree of $\mathrm{p} 73$ downregulation in these tumors correlated with their extranodal dissemination status. These data indicate that $\mathrm{p} 73$ is a modifier of Myc-driven lymphomas in mice, favoring tumor dissemination, and suggest that $\mathrm{p} 73$ could be a biomarker for human $B$ cell lymphoma dissemination, a notion that can now be tested in clinicopathologic correlation studies.
\end{abstract}

\section{Introduction}

The $p 73$ gene was identified through its structural homology with the 53 tumor suppressor $(1,2)$. Initial overexpression studies demonstrated that p73 can activate many p53-responsive genes and partly substitute for $\mathrm{p} 53$ in triggering cell-cycle arrest or apoptosis (3-5). However, p73 and p53 are not functionally equivalent. Recent analyses revealed that $\mathrm{p} 73$ has its own set of transcriptional target genes $(6,7)$. Moreover, the TP73 gene locus is complex and encodes 2 classes of isoforms with opposing activities. p73 variants that lack the $\mathrm{N}$-terminal transactivation (TA) domain function to interfere with the activity of the full-length counterparts of p73, p53, and $\mathrm{p} 63$ $(8,9)$. A net upregulation of the dominant negative $\Delta \mathrm{Np} 73$ isoforms (i.e., a high $\Delta \mathrm{N} / \mathrm{TAp} 73$ ratio) frequently occurs in carcinomas and is a poor prognostic marker in some solid tumors (9-11).

Although p53 and p73 share structural similarities, their differences in vivo are striking. Thus, p53-null mice are developmentally normal but show a high predisposition to spontaneous tumors, mainly $\mathrm{T}$ lymphomas. In contrast, in vivo evidence for a tumor-suppressor role of $\mathrm{p} 73$ is still scarce and contradictory. p73-knockout mice (which lack all p73 isoforms) are born with developmental neurological and immunological defects associated with early lethality, but show no tumor predisposition (12). Flores et al. (13) reported spontaneous development of mainly microscopic tumors in $p 73^{+/-}$and $p 73^{-/-}$mice, particularly when combined with p53 heterozygosity, while p73 did not contribute to 553 suppressor activity during irradiation-induced $\mathrm{T}$ cell lymphomagenesis (14). On the other hand, aging mice specifically lacking TAp73 develop spontaneous malignancies, mainly lung adenocarcinomas and lymphomas (15).

Unlike p53, the $p 73$ gene is rarely mutated in human cancers (10). In fact, there is currently no compelling genetic evidence

Conflict of interest: The authors have declared that no conflict of interest exists. Citation for this article: J Clin Invest. 2010;120(6):2070-2080. doi:10.1172/JCI40331. that inactivation of $\mathrm{p} 73$ is required for malignant transformation or progression in human tumors. The single notable exception comes from persistent reports of frequent loss of $\mathrm{p} 73$ expression in hematological malignancies. Specifically, inactivation of the p73 gene by epigenetic silencing or deletion is a common finding in malignant lymphoproliferative disorders. p73 is inactivated in about $35 \%$ of acute lymphoblastic leukemia (ALL) and about onethird of non-Hodgkin lymphomas (NHLs) (16-19). Of note, 95\% of human lymphomas are B cell in origin (20). Also, in a study of natural killer cell lymphomas, the p73 gene was methylated in $94 \%$ of cases (21). Assessment of p73 methylation may provide important prognostic information, as shown in patients with ALL (19). In sum, these data suggest that p 73 might play a pathogenetic role in human lymphomas.

To experimentally assess the role of p73 in B cell lymphomagenesis, we investigated $\mathrm{E} \mu$-myc transgenic mice, the well-characterized model of human NHL. These mice overexpress c-Myc in B cell progenitors under the control of the immunoglobulin heavy chain enhancer and develop pre-B cell and/or B cell lymphomas $(22,23)$. The latent period prior to onset of disease reflects the ability of c-Myc to induce p53-dependent and p53-independent growth arrest and apoptotic checkpoints that protect animals against tumor formation. These checkpoints become disabled when overtly malignant cells emerge (24). Given the fact that a significant fraction of human B lymphomas exhibit deregulated c-Myc and $\mathrm{p} 73$ and that c-Myc activates proapoptotic functions of $\mathrm{p} 73$ in vitro (25), E $\mu$-myc mice provide a relevant in vivo model to assess the impact of $\mathrm{p} 73$ on tumor behavior.

\section{Results}

p73-deficient Eu-myc mice are viable but show developmental defects. It was reported that $p 73^{--}$mice survive to birth, but most of them die within 2 months due to brain defects, chronic infections, and inflammation (12). Indeed, in mixed litter colonies generated 
A
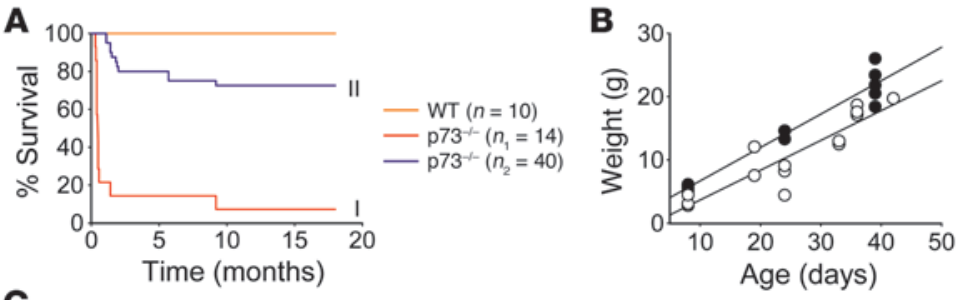

C

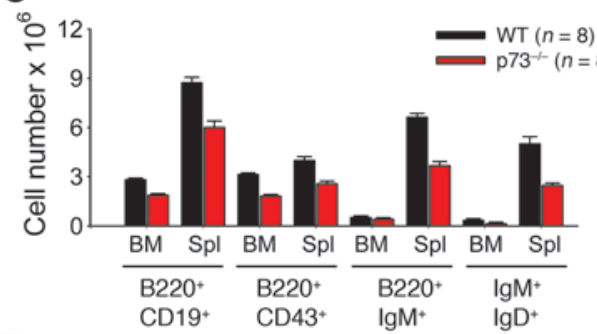

D

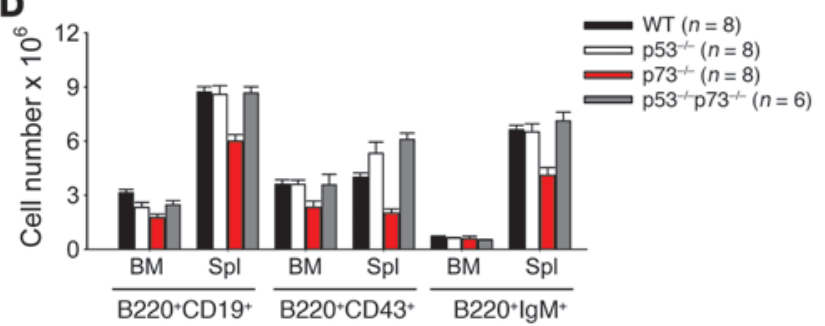

\section{Figure 1}

Mice deficient in p73 have impaired B cell development. (A) Overall survival of WT and $p 73^{-/-}$mice before (curve I) and after (curve II) removal of intralitter competition from WT and $p 73^{+/-}$siblings. The number of animals per genotype is indicated. Curve II: while a minority $(25 \%)$ of $p 73^{-/-}$mice die prematurely due to severe hydrocephalus with intraventricular hemorrhage, the remainder survive long term and remain tumor free. (B) Postpartum body weight gain of WT (black circles) and rescued $p 73^{-/-}$mice (white circles) shown in Figure 1A, curve II. (C) Cells extracted from BM and spleens (Spl) of 4-week-old nontransgenic WT and $p 73^{-/-}$ mice were costained with antibodies to B220, CD19, CD43, $\operatorname{IgM}$, and $\lg \mathrm{D}$ and analyzed by FACS. Absolute numbers of total $B$ cells $\left(B 220^{+} \mathrm{CD} 19^{+}\right)$, pro-B cells $\left(B 220^{+} \mathrm{CD}^{+} 3^{+}\right)$, immature/mature $B$ cells $\left(\mathrm{B}^{2} 20^{+} \mathrm{IgM}^{+}\right)$, and recirculating $B$ cells $\left(\operatorname{lgM}+\lg D^{+}\right)$are graphed. Error bars represent SEM. (D) Cells extracted from BM and spleens of 4-week-old mice of the indicated genotypes were stained and analyzed as in $\mathbf{C}$. Error bars represent SEM. from interbreeding heterozygous animals, survival of $p 73^{-1-}$ mice decreased sharply to less than $20 \%$, as previously described (Figure 1A) (12). However, we discovered that most $p 73^{--}$animals die at this young age mainly because of malnutrition caused by their inability to compete with WT and $p 73^{+/-}$littermates. Identifying such $p 73^{-/-}$ pups right after birth and moving them to lactating foster mothers essentially normalized their weight gain and rescued overall longterm longevity to nearly $80 \%$ (Figure 1, A and B). As reported (12), rescued $p 73^{-/-}$mice developed variably penetrant congenital hydrocephalus, which killed $25 \%$ of them within 9 months due to intraventricular hemorrhage (Figure 1A). Infections, although present, were mild and did not cause death. Of note, none of the long-term $p 73^{-/-}$survivors developed a malignancy. Thus far, we produced more than $40 p 73^{-1-}$ E $\mu$-myc mice, of which $20 \%$ again displayed severe brain defects causing their premature death. Most of the remaining $p 73^{-/-} \mathrm{E} \mu$-myc mice exhibited nonfatal brain defects and developed B cell lymphomas (see below).

To determine whether p73 loss affects normal B cell development, BM and peripheral lymphoid organs (spleen, lymph nodes) of nontransgenic $p 73^{+/+}, p 73^{+/-}$, and $p 73^{-/-}$mice were characterized by flow cytometry. At birth and through 8 weeks of age, lymphoid organs from $p 73^{+/-}$and $p 73^{-/-}$mice displayed no morphological defects and showed an overall normal proportional distribution of B cell subsets, including pro-B cells $\left(\mathrm{B} 220^{+} \mathrm{CD} 43^{+}\right)$, immature/ mature $B$ cells $\left(\mathrm{B}_{22} 20^{+} \operatorname{IgM}^{+}\right)$, and recirculating B cells $\left(\operatorname{IgM}^{+} \operatorname{IgD}^{+}\right)$ (Figure $1 \mathrm{C}$ and data not shown). However, the absolute cell number of each B cell subset in $p 73^{-/-}$mice was decreased by $30 \%-40 \%$ compared with WT controls (Figure 1C). This B cell hypocellularity in $p 73^{-/-}$mice is mediated by $\mathrm{p} 53$, since codeletion of p53 completely rescued B cellularity in $p^{73^{-1-}}$ mice. Accordingly, $p 53^{-/-} p 73^{-/-}$(DKO) mice showed normal numbers of all major $\mathrm{B}$ cell subsets, most notably within the immature BM and mature spleen B cell compartments (Figure 1D). Moreover, B cells from spleens of $\mathrm{p} 3^{-/-}$mice showed increased Puma levels compared with WT mice (Supplemental Figure 1C; supplemental material available online with this article; doi:10.1172/JCI40331DS1). Consistent with this result, we previously showed that inactivation of p73 in primary mouse embryo fibroblasts (MEFs) impairs proliferation due to activation of p53 (26).

We previously showed that $\mathrm{p} 73$ can be a transcriptional target of ectopic Myc in cultured cells (25). In vivo levels of p73 transcripts in premalignant $\mathrm{E} \mu$-myc B cells were mildly higher than those of nontransgenic WT B cells (Figure 2A). This is consistent with the observation that Myc is increased 2- to 4-fold in E $\mu$-myc B cells (data not shown) and that well-studied transcriptional targets of Myc are slightly increased in B cells of these mice. Overall, p73 might be a direct target of Myc regulation in this cell type. The central mechanism of Myc-induced tumorigenesis is an aberrant expansion of immature B cell population in BM, which accounts for most of the malignant growth of the transformed B cells (22, $23,27)$. The absolute number of mature $B$ cells is altered less significantly due to increase in splenic cellularity (Figure 1C). Importantly, forced Myc expression increased the percentage of total $\mathrm{B}$ cells in BM of premalignant E $\mu$-myc mice, independent of the presence or absence of p73 (Supplemental Figure 1A). Furthermore, this B cell hypercellularity was not caused by higher proliferation (Figure 2B) or lower apoptosis (Supplemental Figure 1B), which in fact showed the opposite result in p73-deficient cells, consistent with p53 activation in the absence of p73. The levels of p53 target genes $p 21, B a x$, and Noxa were accordingly increased (Supplemental Figure 1C). However, in contrast to nontransgenic mice, in which $\mathrm{p} 73$ plays no apparent role in the maturation of $\mathrm{B}$ cells (Figure 2C), the absence of $\mathrm{p} 73$ in Myc transgenics shifted the ratio toward maturation. This is indicated by an IgM-negative 

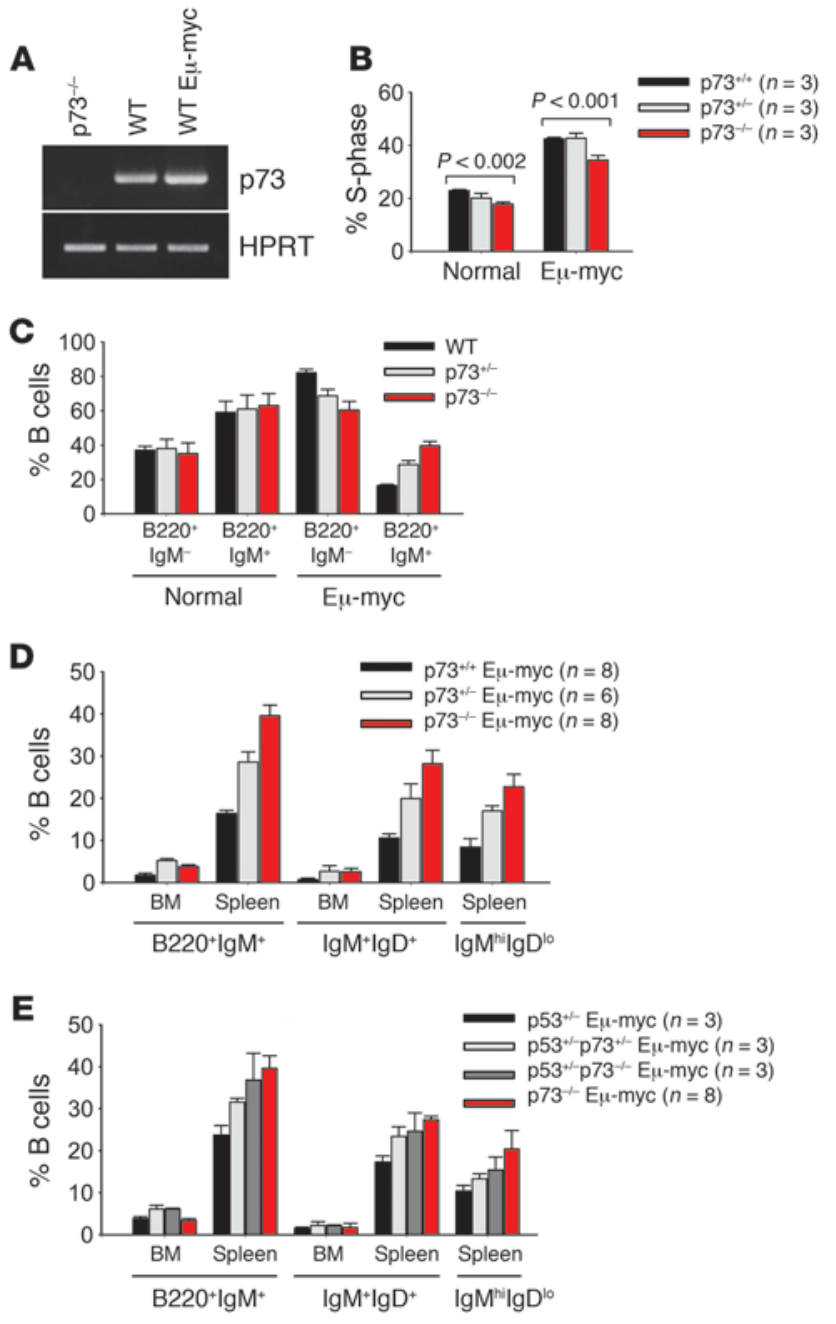

to IgM-positive cell ratio of 5 in WT E $\mu$-myc mice compared with a ratio of only 1.5 in $p 73^{-1-} \mathrm{E} \mu$-myc mice, revealing a 3.3 -fold increase in the proportion of more mature IgM-positive $\mathrm{B}$ cell populations (Figure 2, C and D). Heterozygous $p 73^{+/-}$E $\mu$-myc mice showed an intermediate phenotype. Most of the excess cells in spleens of $p 73^{-1-} \mathrm{E} \mu$-myc mice were $\mathrm{B} 220^{+} \operatorname{IgM}^{+}, \operatorname{IgM}^{\text {hi }} \operatorname{IgD}^{\text {lo, }}$, and $\operatorname{IgM}^{+} \operatorname{IgD}^{+}$ lymphocytes comprising $\mathrm{T} 1$ transitional, marginal zone, and memory B cell subsets (Figure 2D).

In contrast to nontransgenic p73-deficient mice, analysis of premalignant compound E $\mu$-myc mice heterozygous for p53 (p53-null E $\mu$-myc animals could not be analyzed because they die in utero) showed that the differentiation defect associated with p73 deficiency was not significantly rescued by loss of 1 p53 allele and thus is possibly p53-independent (Figure 2E). Based on these aggregate results, we conclude that p73 loss affects $B$ cell numbers by altering their development and/or peripheral differentiation. Moreover, in the context of Myc, the absence of p73 allows increased B cell maturation in premalignant mice.

p73 loss has no discernible effect on disease onset and mortality in Mycinduced lymphomagenesis. WT E $\mu$-myc mice develop fully penetrant, lethal B cell lymphomas starting at 2 months of age $(22,23)$. Most WT E $\mu$-myc mice in our cohort also succumbed to lymphomas within 2-4 months after birth (Figure $3 \mathrm{~A}, n=36$ ). Of note,

\section{Figure 2}

In the context of Myc, the absence of p73 allows increased maturation of premalignant B cells. (A) Semiquantitative RT-PCR analysis of $p 73$ mRNA expression in sorted B220+CD19+ B cells isolated from spleens of $p 73^{--}$, nontransgenic WT and 4 week-old premalignant E $\mu$-myc mice. HPRT, control for equal cDNA input. (B) Proportion of cells in S-phase from total BM of 4-week-old nontransgenic (normal) and premalignant E $\mu$-myc mice of the indicated genotypes. Error bars represent SEM. (C) Cells isolated from spleens of 4-week-old nontransgenic (normal, $n=8$ per genotype) and premalignant $\mathrm{E} \mu$-myc mice ( $n=8$ per genotype) were stained with antibodies to B220 and IgM and analyzed by FACS. The percentage of $B$ cells is indicated. Error bars represent SEM. (D) Cells isolated from BM and spleens of 4-week-old premalignant $E \mu-m y c$ mice of the indicated genotypes were stained with antibodies to B220, $\operatorname{lgM}$, and $\lg \mathrm{D}$. Proportions of mature $\mathrm{B}$ cells $\left(\mathrm{B}^{2} 2 \mathrm{O}^{+} \lg \mathrm{M}^{+}\right)$, recirculating $B$ cells $\left(\operatorname{lgM} \mathrm{M}^{+} \lg D^{+}\right)$, and $\mathrm{T} 1$ transitional and marginal zone $B$ cells $\left(\lg \mathrm{M}^{\text {hi }} /\right.$ $\lg D^{\circ}$ ) are shown. Error bars represent SEM. (E) BM and splenic cells from 3-week-old $E \mu$-myc mice of the indicated p53 and p73 genotypes were analyzed as in D. Error bars represent SEM.

survival of $p 73^{+/-} \mathrm{E} \mu$-myc mice $(n=44)$ and $p 73^{-/-}$E $\mu$-myc mice $(n=30)$ did not differ significantly when Kaplan-Meier survival curves were analyzed by log-rank test $\left(P=0.127\right.$ for WT vs. $p 73^{-1-}$; $P=0.313$ for WT vs. $p 73^{+/-}$; overall $P=0.291$ ). We conclude that p73 loss has no discernible effect on disease onset and mortality in Myc-induced lymphomagenesis.

p53 but not $p 73$ is the dominant tumor suppressor in Myc-induced lymphomagenesis. We next examined lymphoma onset and latency in genetically matched E $\mu$-myc $p 53^{+/-}, p 53^{+/-} p 73^{+/-}$, and $p 53^{+/-} p 73^{-/-}$ mice. As expected, loss of 1 p53 allele accelerated tumor onset and mortality compared with E $\mu$-myc $p 73^{-/-}$mice (Figure 3B). In contrast, loss of 1 or $2 \mathrm{p} 73$ alleles on the $p 53^{+/-}$Myc background had no further impact on survival (Figure 3B). As reported $(28,29)$, tumors arising in the $p 53^{+/-}$Myc background lost the remaining WT p53 allele, consistent with their highly aggressive behavior (Figure 3C), while no loss of heterozygosity ( $\mathrm{LOH}$ ) occurred in the remaining WT p73 allele (Figure 3C). Likewise, single $p 73^{+/-}$Myc lymphomas showed no loss of the remaining WT p73 allele (Figure $3 \mathrm{D}$ ). In sum, these results indicate that p53 but not $\mathrm{p} 73$ is the dominant tumor suppressor in Myc-induced lymphomagenesis.

Loss of 73 promotes dissemination of E $\mu$-myclymphomas. Histologically, no consistent difference was seen in the morphologic appearance of E $\mu$-myc $p 73^{+/+}$and $p 73^{-/-}$lymphomas (Supplemental Figure 2). However, loss of p73 induced a marked alteration in the clinical phenotype of E $\mu$-myc lymphomas. Thus, $p 73^{+/+}$E $\mu$-myc lymphomas invariably presented as bulky nodal disease with massive splenomegaly and general lymphadenopathy that was easily palpable and dominated the disease picture (representative examples shown in Figure 4, A and B, and Supplemental Figure 3). Eventually, at the advanced stage of disease, tumor dissemination to BM and some other organs occurred (Table 1) $(22,23)$.

In contrast, a consistent feature of lymphomas arising in $p 73^{-/-}$ E $\mu$-myc mice was a lack of the gross degree of splenomegaly and massive lymphadenopathy. Thus, the average nodal tumor burden (spleen weight and combined lymph node weight) of moribund $p 73^{-/-}$E $\mu$-myc was reduced by $33 \%$ and $68 \%$, respectively, compared with their $p 73^{+/+}$E $\mu$-myc controls (Figure 4B). Instead of bulky nodal tumors, the disease of tumor-bearing $p 73^{-1-}$ E $\mu$-myc mice was marked by systemic signs of illness, including severe apathetic appearance, heavy breathing, and the inability to take food and water. Mice of all genotypes were sacrificed when the strictly 

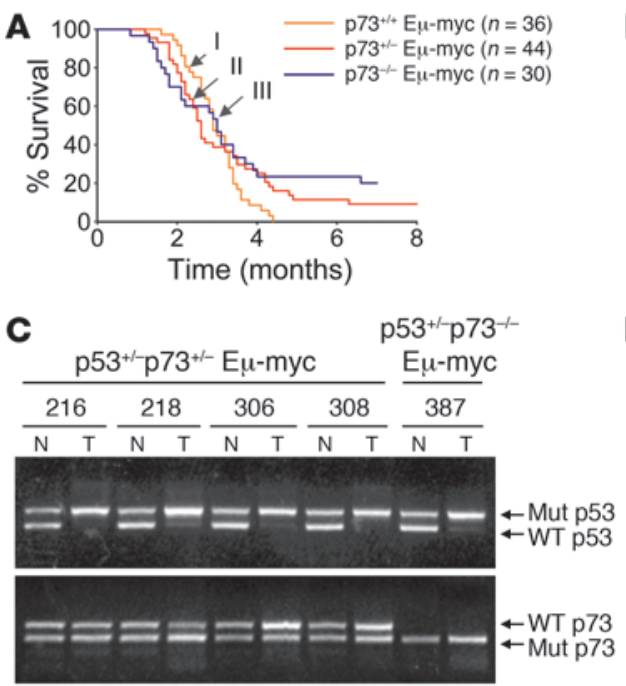

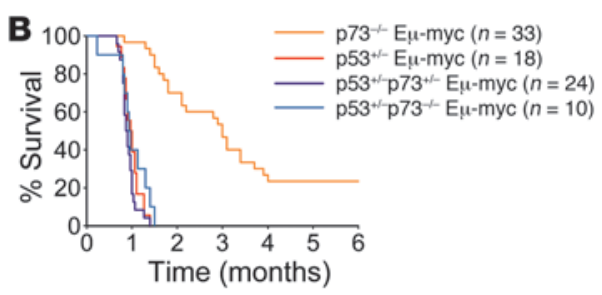

D

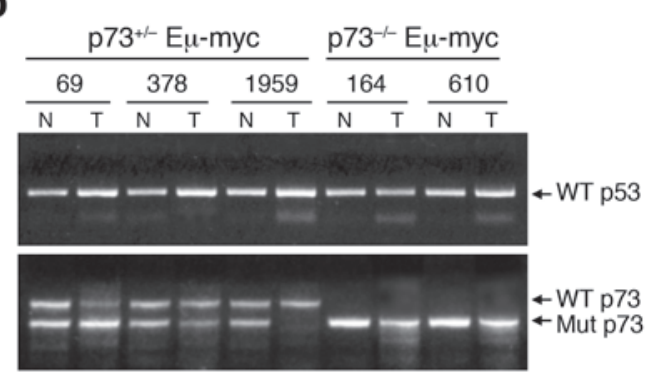

Figure 3

p73 deficiency has no discernible effect on disease onset and mortality in Myc-driven lymphomagenesis. (A)

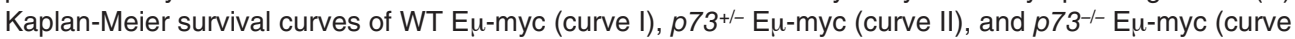
III) mice. The number of animals per genotype is indicated. (B) Kaplan-Meier survival curves of E $\mu$-myc mice of the indicated p53 and p73 genotypes. (C and D) LOH analysis at the p53 and p73 loci by genomic PCR of matched pairs of normal $(\mathrm{N})$ and tumor $(T)$ tissues derived from $E \mu$-myc $p 53^{+/-} p 73^{+/-}$and $E \mu$-myc $p 53^{+-} p 73^{-/-}$mice (C) or from E $\mu$-myc $p 73^{+--}$and E $\mu$-myc $p 73^{-/-}$mice (D). Individual animals are indicated.

defined experimental end point was reached (see Methods). Histological analysis showed that the clinical disease of $p 73^{-/-} \mathrm{E} \mu-$ myc mice was mainly due to widespread tumor dissemination, the extent of which was considerably higher compared with that of $p 73^{+/+}$E $\mu$-myc animals (examples in Supplemental Figure 4). Conversely, when tissues from E $\mu$-myc $p 73^{+/+}$and $p 73^{-/-}$mice were compared whose lymphadenopathy was equal in extent, control tumors were not disseminated but limited to spleens and lymph nodes (data not shown). One third of $p 73^{+--}$and $p 73^{-/-}$E $\mu$-myc mice showed dissemination to the lung (Table 1 and Figure 4C), an organ not affected in our control cohort, regardless of tumor burden or leukemic status. Furthermore, while meningeal involvement in control mice was mild, affecting the leptomeninges in 30\% of preterminal animals, it was extensive, with massive thickening of the dura mater and leptomeninges in $70 \%$ of $p 73^{-/-} \mathrm{E} \mu$-myc mice (Table 1). Likewise, while spread to brain parenchyma occurred in $33 \%$ of control mice, $83 \%$ of $p 73^{-/-} \mathrm{E \mu}$ myc mice were affected (Table 1 and Figure 4C). One of the most striking dissemination patterns found in all $p 73^{-/-} \mathrm{E} \mu$-myc mice was the presence of macroscopically apparent lymphomatous tumor masses ("ridges") running symmetrically along the vertebral column (Table 1 and Supplemental Figure 4). Histologically, these tumor masses had completely effaced paravertebral skeletal muscles and soft tissues. In contrast, only $10 \%$ of control mice were affected (Table 1). Interestingly, the incidence of leukemia was similar between the genotypes (Table 1), suggesting that the widespread tumor dis-

\section{Table 1}

Lymphoma dissemination in E $\mu$-myc mice with 2, 1, or 0 p73 alleles

\begin{tabular}{|c|c|c|c|}
\hline Genotype & $p 73^{+/+}$ & $p 73^{+/-}$ & $p 73^{-/}$ \\
\hline & $n=15$ & $n=10$ & $n=15$ \\
\hline Thymus ${ }^{A}$ & $75 \%$ & $75 \%$ & $80 \%$ \\
\hline Liver & $90 \%$ mild & $90 \%$ mild & $90 \%$ mild \\
\hline Intestine & $70 \%$ minimal & $50 \%$ minimal & $60 \%$ minimal \\
\hline Kidney & $25 \%$ minimal & $10 \%$ minimal & $15 \%$ minimal \\
\hline Leukemia & $40 \%$ & $50 \%$ & $40 \%$ \\
\hline Lung & $0 \%$ & $33 \%$ & $33 \%$ \\
\hline Meninges & $30 \%$ lepto, mild & $33 \%$ & $70 \%$ dura and lepto, extensive \\
\hline Brain parenchyma & $33 \%$ & $33 \%$ & $83 \%$ multifocal \\
\hline Paravertebral "ridges" & $10 \%$ absent or mild & $60 \%$ mild to severe & $100 \%$ moderate to severe \\
\hline
\end{tabular}

${ }^{A}$ Equal range from minimal to severe in all genotypes. semination into extranodal and extralymphoid tissues upon p73 loss was not simply due to leukemic conversion.

The enhanced dissemination propensity of $p 73^{-/-}$compared with $p 73^{+/+}$lymphoma cells was also reproducible in nude mouse assays. After tail vein injection, $p 73^{-/-} \mathrm{E} \mu$-myc lymphoma cells showed greater degree of extranodal growth compared with WT E $\mu$-myc controls (Figure 4D). In mice receiving $p 73^{-/-}$tumor cells, the entire viscera in the abdominal cavity were completely overrun by tumor masses. Dissemination also extended into abdominal muscles, the paravertebral regions, lymph nodes, brain, lung, and skin. Collectively, these data demonstrate that $p 73^{-/-}$E $\mu$-myc lymphomas exhibit a greater propensity for widespread dissemination and extranodal growth than WT E $\mu$-myc control tumors, which is the single major cause of death in tumor-bearing $p 73^{-/-} \mathrm{E} \mu$-myc mice.

As already seen with premalignant B cells (Figure 2, C and D), p73 loss also allowed increased maturation in malignant $\mathrm{B}$ cells. Thus, $90 \%$ of p73-null lymphomas $(n=15)$ expressed surface IgM, indicating a more mature B cell phenotype, compared with only $50 \%$ of $p 73^{+/+}$lymphomas $(n=14)$ (Figure 4E; $P=0.050$, 2-tailed Fisher's exact test). In support, $p 73^{-/-}$lymphomas tended to express increased levels of activation-induced cytidine deaminase (AID) (Figure 4F; 7 randomly chosen lymphomas per genotype), an enzyme normally required in mature $\mathrm{B}$ cells for antibody diversification via class switch recombination and somatic hypermutation. When constitutively expressed, AID is involved in germinal center-derived mature B lymphomagenesis by generating DNA double-strand breaks in off-target genes $(30,31)$. Taken together, while half of our WT E $\mu$ myc lymphomas were immature lymphoblastic pre-B lymphomas 
A
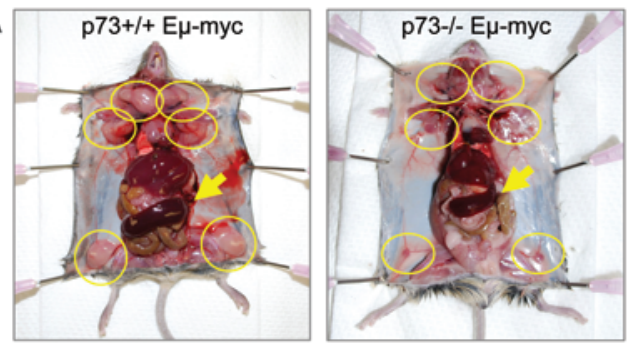

B
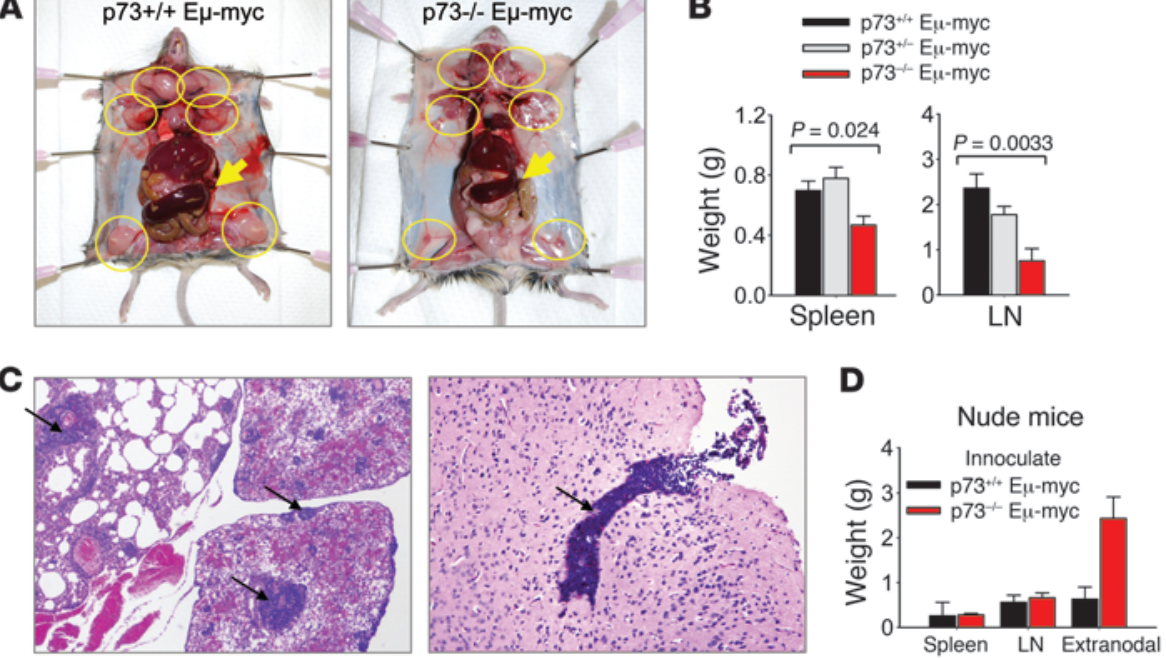

E

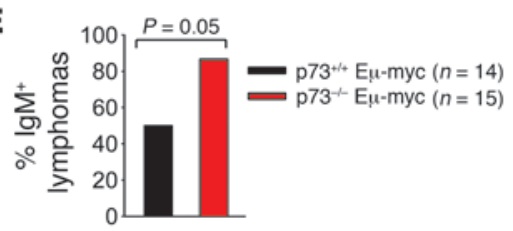

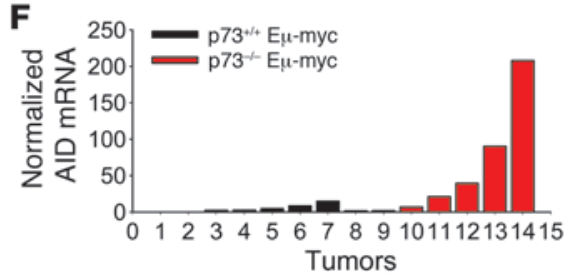

\section{Figure 4}

Loss of p73 promotes dissemination of $\mathrm{E} \mu$ myc lymphomas. (A) Representative moribund $p 73^{+/+} \mathrm{E} \mu$-myc and $p 73^{-/-} \mathrm{E} \mu$-myc mice are shown. Arrows, spleens; circles, lymph nodes. For comparison, spleens have been placed on top of the bowel. (B) Average weight of spleen and lymph nodes (compound per animal) from moribund E $\mu$-myc $p 73^{+/+}$, $p 73^{+-}$, and $p 73^{-/-}$mice. Error bars represent SEM derived from 20 mice of each genotype. (C) Histological examination (H\&E staining) of lymphoma dissemination in $p 73^{-1-} \mathrm{E} \mu$-myc mice. Arrows denote lymphomatous infiltrates in lung and brain parenchyma. Original magnification, $\times 4$ (left); $\times 10$ (right). (D) Weight of reconstituted lymphomas in nude mice inoculated with $\mathrm{E} \mu$-myc $p 73^{+/+}$and $p 73^{-/-}$lymphoma cells $\left(1 \times 10^{6}\right.$ cells each). Error bars represent SEM from 4 independent experiments. (E) Immunophenotyping of tumors from $p 73^{+/+}$ and $p 73^{--}$E $\mu$-myc mice with B220, CD19, and IgM antibodies. Tumors were classified as either predominantly (>80\%) IgM-positive (mature) or IgM-negative (immature). ( $F$ ) Quantitative real-time RT-PCR analysis of AID in E $\mu$-myc $p 73^{+/+}$and $p 73^{-/-}$lymphomas (7 random tumors per genotype).
(23), $p 73^{-/-} \mathrm{E} \mu$-myc tumors were predominantly mature aggressive tumors. As such, they display a higher incidence of features resembling diffuse large B cell lymphoma (DLBCL), an important and diverse group of mature aggressive human $B$ cell neoplasms with a high propensity for extranodal dissemination (32).

p73 loss does not confer a proliferative or survival advantage to tumor cells. Impaired apoptosis is central to tumor development. However, contrary to expectations, $\mathrm{p} 73$ loss did not confer a growth or survival advantage to the cell. Premalignant $p 73^{-/-}$E $\mu$-myc B cells from BM did not show an increase in proliferation (Figure $2 \mathrm{~B}$ ) or a decrease in apoptosis (Supplemental Figure 1B). Likewise, malignant $p 73^{+/+}$ and $p 73^{-/-}$lymphomas did not differ in their proliferative rates (Figure 5, A and B, and data not shown) and spontaneous apoptosis rates (Figure $5 \mathrm{C}$ ). Furthermore, $p 73^{-/-} \mathrm{E} \mu$-myc tumor cells did not grow well in vitro and rapidly died upon exposure to genotoxic drugs, similar to $p 73^{+/+}$tumor cells (Figure 5D). In contrast, tumors derived from $p 53^{+/-} p 73^{-/-} \mathrm{E} \mu$-myc mice were refractory to apoptosis (Figure 5D). Thus, although p73 is thought to be one of the downstream mediators of Myc-induced apoptosis in solid cancers (4, 5, $11,25)$, p73 loss in E $\mu$-myc B cells in vivo does not confer an apoptosis defect. This situation is reminiscent of MEFs, in which c-Myc sensitization of etoposide-induced apoptosis is similar between WT and $p 73^{-1-}$ MEFs (8). Of possible interest in this context, c-Myc was reported to physically bind to p73, thereby impairing p73's transcriptional activity on the Bax and $\mathrm{p} 21$ promoters (33).

In addition to changes in the clinical course and immunophenotype, loss of p73 influenced tumor cytogenetics. Lymphomas from E $\mu$-myc $p 73^{+/+}$and $p 73^{+/-}$mice were characteristically aneuploid. In contrast, most $p 73^{-/-}$E $\mu$-myc lymphomas did not display aneuploidy but remained pseudodiploid, as determined by flow cytometry and spectral karyotyping (Supplemental Figure 5 and data not shown).
Because lymphomas arising in WT E $\mu$-myc mice frequently mutate the $\mathrm{p} 19 \mathrm{ARF} / \mathrm{p} 53$ pathway $(29,34)$, we next evaluated p53 and ARF status in tumors arising in $p 73^{--} \mathrm{E} \mu$-myc mice. Interestingly, while the expected proportion of WT E $\mu$-myc lymphomas either sustained inactivating p53 mutations (e.g., tumors 74 and 136, sequence confirmed), Mdm2 overexpression (e.g., tumor $140)$, or other unknown mutations impinging on the pathway (e.g., tumor 13) that collectively are all reflected by aberrant ARF upregulation, $p 73^{-/-}$E $\mu$-myc lymphomas did not exhibit high levels of p53 protein indicative of p53 mutations (Figure 5E). Sequencing full-length p53 cDNAs from 12 p73-null lymphomas (including tumors shown in Figure 5E) confirmed their WT p53 status. Although WT E $\mu$-Myc B cells express very low levels of ARF protein as long as disease is latent (35), mutations of p53 disrupt the p53ARF negative-feedback loop, resulting in strong induction of ARF levels (24). Conversely, the p53 pathway can be crippled by a complete loss of ARF expression (24), even though ARF inactivation is itself insufficient to trigger lymphomagenesis in E $\mu$-myc mice (35).

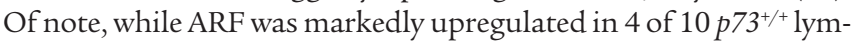
phomas, ARF levels remained low in all $p 73^{-/-}$lymphomas (Figure $5 \mathrm{E})$. Relative quantitation by real-time PCR in individual tumors confirmed that Arf mRNA levels in WT E $\mu$-myc lymphomas varied widely, including greatly increased levels in 2 cases and undetectable levels in 4 cases. In contrast, Arf mRNA levels displayed little or no change in tumors of $p 73^{-/-} \mathrm{E} \mu$-myc mice compared with their premalignant $p 73^{-1-} \mathrm{E} \mu$-myc controls or WT E $\mu$-myc B cells (Figure $5 \mathrm{~F})$, confirming WT p53 status of $p 73^{-/-}$tumors. Thus, we surmise that cryptic mutations other than those causing p53 and/or Arf loss of function accompany the conversion of premalignant $p 73^{-/-}$ E $\mu$-myc B cells to tumor cells.

p73 loss deregulates expression of genes involved in lymphocyte homing and lymphoma dissemination. As a step toward characterizing tran- 
A

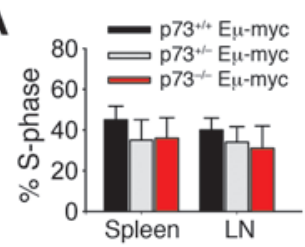

C

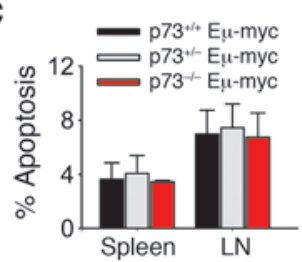

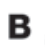

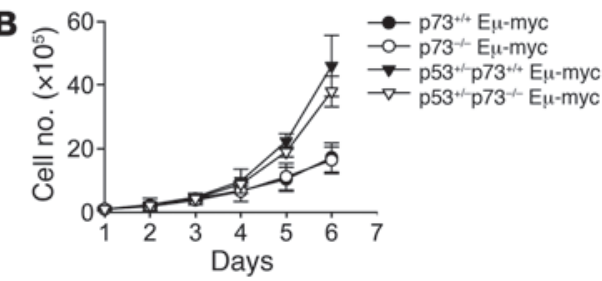

D

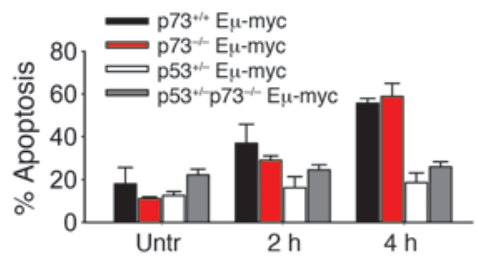

E

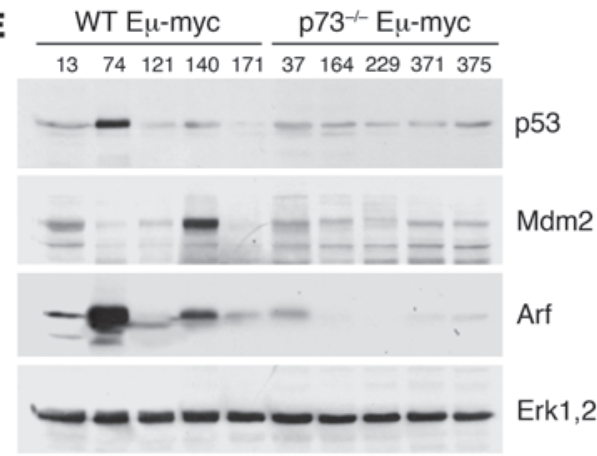

$\mathbf{F}$

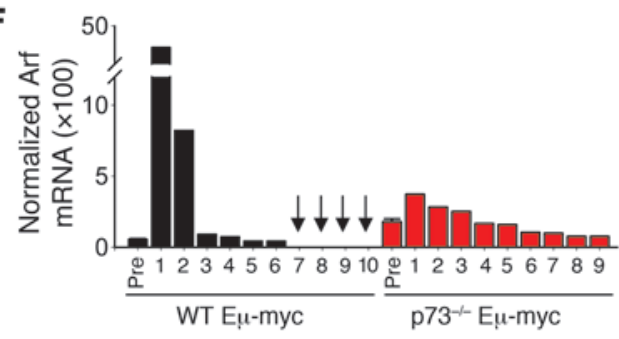

$\frac{\text { WT E } \mu-m y c}{678136142698543} \frac{p 73^{-1-} E \mu-m y c}{609610617944974}$
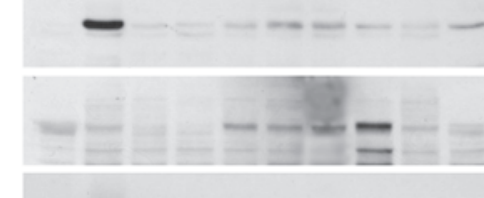

p53

Mdm2

Arf

Erk1,2

\section{Figure 5}

p73 loss does not confer a proliferative or survival advantage to tumor cells. (A) S-phase proportion of cells in primary tumors derived from spleens and lymph nodes of $E \mu$-myc mice of the indicated genotypes ( $n=10$ per genotype). (B) In vitro growth curves of $\mathrm{E} \mu$-myc lymphoma cell lines of the indicated genotypes (2 lines each). Identical results were obtained with 2-hour pulse labeling by BrdU. (C) Spontaneous apoptosis in primary tumors from spleens and lymph nodes ( $n=10$ per genotype). (D) In vitro apoptosis in lymphoma cells (3 cell lines per genotype) that were challenged with $2 \mu \mathrm{g} / \mathrm{ml}$ etoposide for 2 or 4 hours. FACS analysis of propidium iodine-stained (A) or annexin V/ propidium iodine-stained (C and $\mathbf{D}$ ) cells. Error bars represent SEM (A-D). (E) Immunoblot analysis of p53, Mdm2, and Arf expression in E $\mu$-myc $p 73^{+/+}$ and $p 73^{--}$lymphomas. Tumor numbers are indicated. Erk1,2, loading control. (F) Arf mRNA expression, determined by quantitative real-time RT-PCR. Total RNA was isolated from B cells of premalignant (Pre) ( $n=3$ mice per genotype) or tumor-bearing $p 73^{+/+}(n=10)$ and $p 73^{-/-}(n=9)$ E $\mu$-myc mice. Numbers denote individual tumors. HPRT levels were used for normalization. Error bars represent SEM. scriptional profiles that might be relevant in lymphoma dissemination promoted by $\mathrm{p} 73$ deficiency, we performed expression analyses of representative tumors from E $\mu$-myc $p 73^{+/+}$and $p 73^{-/-}$mice. Only tumors with WT p53 were chosen. A total of 822 genes were differentially regulated by at least 2 -fold in $p 73^{-/-}$compared with $p 73^{+/+}$ lymphomas. Of these, 377 genes were upregulated, while 445 were downregulated in $p 73^{-/-}$tumors. Some of these genes were reported as direct target genes of $\mathrm{p} 73$ and/or $\mathrm{p} 53$ regulation. Within the upregulated genes, Timp2 is a p73 target (36), Ptpre is a validated novel p53 target, and 5 genes (Alox5, Marco, Chn2, Abcb9, and Gas6) contain ChIP/PET-verified p53 response elements (37). Within the downregulated genes, Jag2, Trim32, Cth, Idh2, Arntl, and Xrcc6 were reported as direct $\mathrm{p} 73$ targets $(36,38)$, Nck2 is a validated novel p53 target, and 7 genes (Ank, Eno1, Pcnx, Kcnk1, Pmvk, Ddit4, and Tle1) contain ChIP/PET-verified p53 response elements (37).

Interestingly, based on Gene Ontology (GO) classification, a large group of up- and downregulated genes (31\%, 116 of 377 ; and $15 \%, 67$ of 445 , respectively) in disseminating p73-null lymphomas encoded cell-surface proteins involved in cell adhesion and receptor signaling (Supplemental Table 1; PANTHER functional annotation). For example, p73-null tumors showed upregulation of cell adhesion molecules integrin $\alpha \mathrm{L}$, integrin $\beta$, integrin $\alpha \mathrm{X}$, and L-selectin. Moreover, p73-null tumors showed upregulation of chemokine receptors (Ccr2, Ccr5, Ccr6, Cxcr3, Cxcr5, and Cxcr6), chemokine ligands ( $\mathrm{Cxcl} 4, \mathrm{Ccl} 5$, and $\mathrm{Ccl} 6)$, and cytokine receptors (Csf2rb2, Csf3r, Il18r1, Il27ra, and Lifr) (Table 2). Additional deregulated genes in p73-null tumors included hematopoietic stem and progenitor cell-, myeloid lineage-, NK cell lineage-, and T cell lineage-associated genes (Table 2). Of note, adhesion molecules such as L-selectin and integrin $\beta 7$ as well as chemokine receptors such as CXCR5 are implicated in lymphocyte homing and dissemination of human lymphomas (reviewed in ref. 39). Twenty-three cellsurface genes, shown in Tables 2 and 3, were extensively validated by quantitative real-time RT-PCR in primary malignant lymphomas and premalignant B cells from BM (Figure 6, A and B, and Supplemental Figure 6A). Both premalignant and malignant samples showed consistent p73-dependent changes in the expression profiles of specific genes, indicating that their changes are specific, robust, and occur early during lymphomagenesis (Figure 6, A and B, and Supplemental Figure 6A).

In addition, we asked whether shared deregulated genes exist between disseminating mouse $\left(p 73^{-/-} \mathrm{E} \mu\right.$-myc) and disseminating human B lymphomas. To this end, we queried a published annotated human database of 221 mature aggressive B lymphomas that 


\section{Table 2}

p73 loss in E $\mu$-myc lymphoma deregulates expression of genes involved in cell adhesion and receptor signaling that are implicated in lymphocyte homing and human lymphoma dissemination

\begin{tabular}{|c|c|c|c|}
\hline Gene symbol & Gene name & Fold change $\left(\log _{2}\right)$ & $P$ value \\
\hline \multicolumn{4}{|c|}{ Cell adhesion molecules } \\
\hline Itgal & Integrin alpha L, CD11A & 1.578690254 & $2.00 \times 10^{-5}$ \\
\hline $\operatorname{ltg} b 7$ & Integrin beta 7 & 3.361727127 & $1.08 \times 10^{-8}$ \\
\hline Sell & L-selectin & 1.73181837 & $1.82 \times 10^{-6}$ \\
\hline Itgax & Integrin alpha $X$ & 1.189589482 & $2.75 \times 10^{-5}$ \\
\hline Ifitm3 & Interferon-induced transmembrane protein 3 & 1.827734758 & $3.85 \times 10^{-5}$ \\
\hline \multicolumn{4}{|c|}{ Chemokine receptors } \\
\hline Ccr2 & Chemokine (C-C motif) receptor 2 & 1.106851386 & $2.05 \times 10^{-5}$ \\
\hline Ccr5 & Chemokine (C-C motif) receptor 5 & 1.077494852 & $3.88 \times 10^{-5}$ \\
\hline Ccr6 & Chemokine (C-C motif) receptor 6 & 1.441494716 & $5.99 \times 10^{-6}$ \\
\hline Cxcr3 & Chemokine (C-X-C motif) receptor 3 & 1.159909187 & $7.83 \times 10^{-5}$ \\
\hline Cxcr5 & $\begin{array}{l}\text { Chemokine (C-X-C motif) receptor } 5 \text {, } \\
\text { Burkitt lymphoma receptor } 1 \text { (Blr1) }\end{array}$ & 2.091135729 & $1.82 \times 10^{-6}$ \\
\hline Cxcr6 & Chemokine (C-X-C motif) receptor 6 & 1.08243399 & $9.19 \times 10^{-5}$ \\
\hline \multicolumn{4}{|c|}{ Chemokine ligands } \\
\hline Cxc/4 & Chemokine (C-X-C motif) ligand 4 & 1.32766983 & $5.35 \times 10^{-5}$ \\
\hline Ccl5 & Chemokine (C-C motif) ligand 5 & 2.30735947 & $2.10 \times 10^{-7}$ \\
\hline Cc/6 & Chemokine (C-C motif) ligand 6 & 2.512559223 & $2.45 \times 10^{-7}$ \\
\hline \multicolumn{4}{|c|}{ Cytokine receptors } \\
\hline Csf2rb2 & Colony-stimulating factor 2 receptor, beta 2 & 1.499594383 & $1.17 \times 10^{-5}$ \\
\hline Csf3r & Colony-stimulating factor 3 receptor, granulocyte & 1.073218776 & $1.80 \times 10^{-5}$ \\
\hline $1 / 18 r 1$ & Interleukin 18 receptor 1 & 1.032430758 & $4.71 \times 10^{-5}$ \\
\hline II27ra & Interleukin 27 receptor, alpha & 1.500732887 & $7.49 \times 10^{-6}$ \\
\hline Lifr & Leukemia inhibitory factor receptor & 1.169730543 & $4.67 \times 10^{-5}$ \\
\hline \multicolumn{4}{|c|}{ Hematopoietic stem and progenitor associated } \\
\hline Cd34 & CD34 antigen & 1.151022982 & $1.93 \times 10^{-5}$ \\
\hline Cd52 & CD52 antigen & 2.590008998 & $1.00 \times 10^{-5}$ \\
\hline \multicolumn{4}{|c|}{ Myeloid lineage associated } \\
\hline Cd68 & CD68 antigen & 1.193065414 & 1. $64 \times 10^{4}$ \\
\hline Cd300lf & CD300 antigen-like family member $\mathrm{F}$ & 1.350391436 & $1.63 \times 10^{-5}$ \\
\hline \multicolumn{4}{|c|}{ NK lineage associated } \\
\hline Cd96 & CD96 antigen & 1.196468788 & $2.97 \times 10^{-5}$ \\
\hline Cd244 & CD244 natural killer cell receptor 2B4 & 1.933225205 & $8.14 \times 10^{-7}$ \\
\hline \multicolumn{4}{|c|}{ T lineage associated } \\
\hline $\mathrm{Cd} 2$ & CD2 antigen & 1.250522156 & $5.93 \times 10^{-5}$ \\
\hline$C d 3 g$ & CD3 antigen, gamma polypeptide & 2.574810437 & $2.23 \times 10^{-7}$ \\
\hline Cd3d & CD3 antigen, delta polypeptide & 3.167400834 & $2.40 \times 10^{-7}$ \\
\hline$C d 5$ & CD5 antigen & 2.555166265 & $1.39 \times 10^{-7}$ \\
\hline$C d 6$ & CD6 antigen, transcript variant 2 & 1.747161954 & $1.52 \times 10^{-6}$ \\
\hline Cd8b1 & CD8 antigen, beta chain 1 & 4.521213686 & $3.25 \times 10^{-9}$ \\
\hline Cd83 & CD83 antigen & 1.969812658 & $3.52 \times 10^{-6}$ \\
\hline Thy 1 & Thymus cell antigen 1 , theta & 3.87025413 & $4.46 \times 10^{-9}$ \\
\hline
\end{tabular}

ExN) and 66 presented as nodal (N) lymphomas. A statistically significant correlation between incidence and degree of p73 downregulation and lymphoma dissemination was identified. In extranodal tumors, 66\% (43 of 65 cases) exhibited downregulated p73 compared with only $47 \%$ (31 of 66 cases) of nodal tumors $(P=0.0345)$ (Figure 7B). Moreover, extranodal lymphomas exhibited lower $\mathrm{p} 73$ expression than nodal lymphomas (Figure 7C; all 131 cases; $P=0.01609)$. This correlation was further strengthened within the "low p73" subset of lymphomas (i.e., those with over 2 -fold p73 downregulation compared with the mean of the entire 221 case cohort) (Figure 7C; $P=0.0000502)$. The 31 downregulated nodal cases consisted of $7 \mathrm{mBL}, 7$ intermediate type, and 17 non-mBL. The 43 downregulated extranodal cases consisted of $15 \mathrm{mBL}, 10$ intermediate type, and 18 non-mBL lymphomas.

Interestingly, among the 445 downregulated mouse genes, 35 genes (8\%) are codownregulated in all disseminating mouse and human lymphomas (Table 3 and Supplemental Figure $6 \mathrm{~B})$. Among them are 9 cell-surfaceexpressed genes. These include Ryk, a member of the receptor tyrosine kinase family that functions as a receptor for Wnt proteins; thrombomodulin, a cell-surface anticoagulant glycoprotein; and integral membrane protein $2 \mathrm{~A}$, which is normally induced during thymocyte selection and $T$ cell activation (Table 3 and Figure 6B).

Furthermore, when each case was analyzed individually, $92 \%$ of the extranodal human lymphomas (60 of the 65 cases) shared at least $50 \%$ of their downregulated gene list with the downregulated mouse gene list derived from $p 73^{-/-} \mathrm{E} \mu$-myc mice with disseminating lymphoma. Conversely, $17 \%$ of extra-

had been characterized in great detail (GEO GSE4475) (40). Based on transcriptional and genomic profiling, tumors belonged to 1 of 3 groups (molecular Burkitt lymphoma [mBL]; intermediate group; and non-mBL, the latter largely corresponding to DLBCL and primary mediastinal large B cell lymphoma). Of note, p73 expression was downregulated in $82 \%$ of the human $\mathrm{mBL}$ lymphomas and in $49 \%$ of the intermediate and non-mBL lymphomas (Figure 7A). This confirms and extends previous studies that report loss of $\mathrm{p} 73$ expression in nearly one-third of non-Hodgkin B lymphomas (16-19).

We next analyzed in the human lymphoma cohort whether p73 downregulation is relevant to dissemination. Dissemination status was known for 131 of these 221 tumors, of which 65 presented as extranodal (with or without additional nodal disease, grouped as nodal human lymphomas (11 of 65 cases) shared at least $50 \%$ of their upregulated gene list with the upregulated mouse gene list. Among them, 9 genes overlapped, in that they were upregulated in all disseminating mouse and those human lymphomas with more than $50 \%$ overlap, i.e., the subset of $17 \%$ (Table 3 and Supplemental Figure 6B). (In a random overlap model one would expect 0.198 genes.) Five of these 9 genes were cell-surface genes. They included interferon-induced transmembrane protein 3 (Ifitm 3), normally expressed on migratory primordial germ cells modulating cell adhesion. Ifitm 3 acts as a homing signal and enables cells to respond to environmental cues that guide their localization (41). Other notable genes are the colony-stimulating factor 3 receptor $(C s f 3 r)$ and zyxin, a cytoskeletal protein involved in cell adhesion (42) (Figure 6B). In 

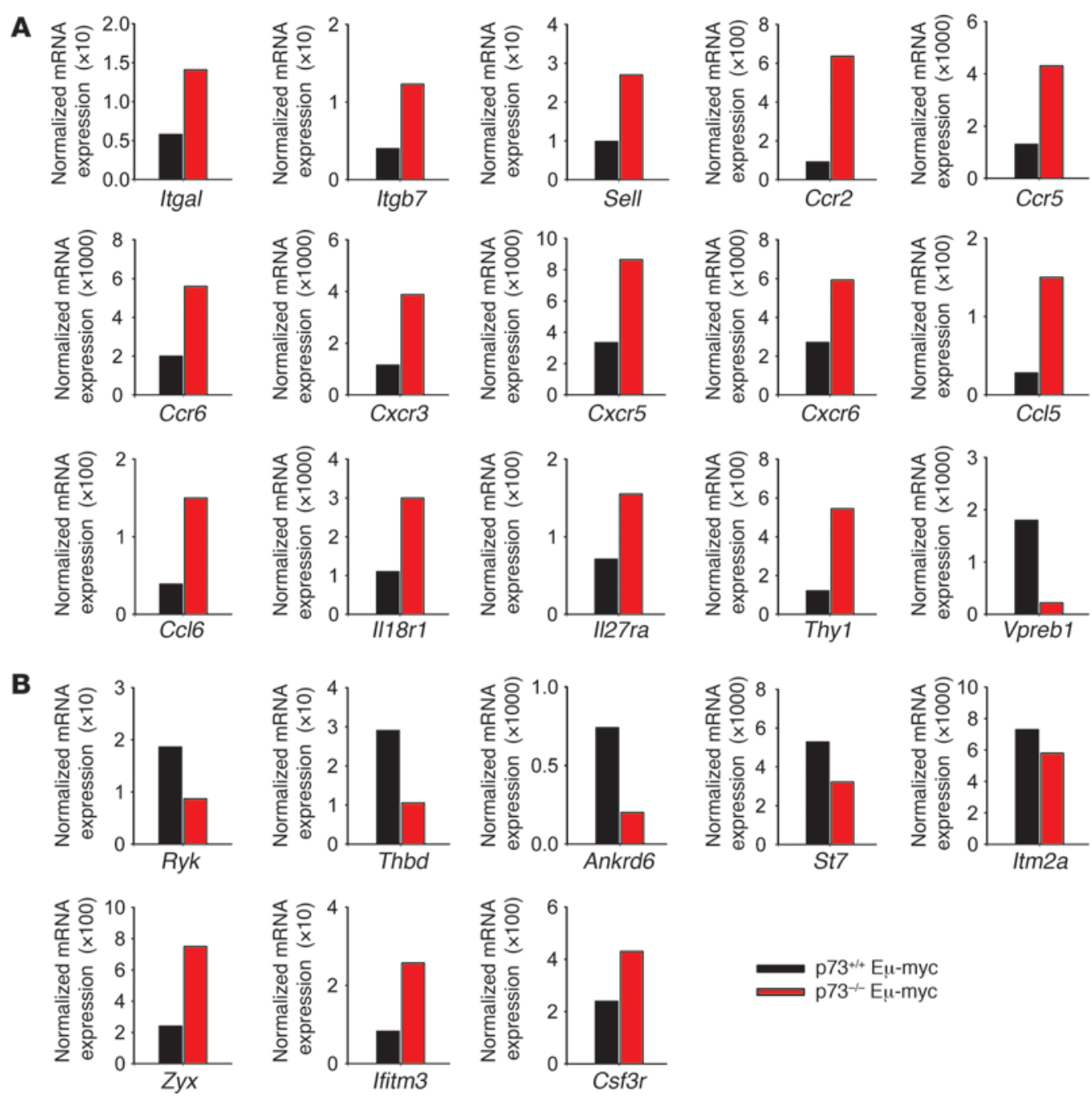

Figure 6

Validation of select genes from microarray analysis by quantitative real-time RT-PCR. (A and B) Quantitative real-time RT-PCR analysis of genes relevant to tumor dissemination in E $\mu$-myc mice. In B, the selection is based on overlap of deregulated genes in mouse and human $\mathrm{B}$ lymphomas. Shown are average expression levels in WT and $p 73^{-/-}$E $\mu$-myc lymphomas (5 pooled tumors per genotype, equal cDNA input per tumor, all tumors harbor WT p53). HPRT used for normalization, samples run in duplicate.

sum, p73 loss associated with mouse lymphoma dissemination alters the transcriptome significantly, including deregulated expression of cell-surface genes known to be involved in lymphocyte homing and dissemination of human lymphomas (39).

\section{Discussion}

Here we provide what we believe are novel insights into the role of p73 in B cell lymphomagenesis using the E $\mu$ - myc model. We show that p73 plays an important function in normal B cell development, since its depletion decreases immature and mature $\mathrm{B}$ cell populations in primary and secondary lymphoid organs by $30 \%-40 \%$ in a p53-dependent manner. Interestingly, we discovered that the shortened lifespan of nontransgenic $p 73^{--}$mice can be rescued, enabling us to follow onset and development of B lymphomas after crossing them with E $\mu$-myc mice. We found that p73 loss has no discernible effect on disease onset and mortality in Mycdriven lymphomagenesis. Instead, the main effect of p73 loss in this context is an altered course of disease associated with a change in clinical phenotype, whereas effects on cell growth or apoptosis, as one might have expected from p73 studies in cultured cells, are not observed. The phenotype of p73-null E $\mu$-myc mice compared with WT E $\mu$-myc controls is characterized by decreased nodal disease in lymphoid organs, but increased propensity to widespread extranodal dissemination. While 50\% of WT E $\mu$-myc lymphomas in our cohort were immature surface IgM-negative pre/pro-B lymphoblastic tumors $(23,43), 90 \%$ of p73-null E $\mu$-myc mice developed more mature surface IgM-positive B cell neoplasms. As such, they displayed a higher incidence of features resembling DLBCL, a major group of mature aggressive human B cell neoplasms with a high propensity for extranodal dissemination (32). Of note, dissemination in human DLBCL confers a poorer prognosis (44).

To delineate functional distinctiveness versus redundancy between p73 and p53, we generated E $\mu$-myc compound mice deficient in both genes. Our results indicate functional complementarity, in that p53 acts as the dominant tumor suppressor in the onset of B lymphomas, while p73 is a tumor modulator 
A

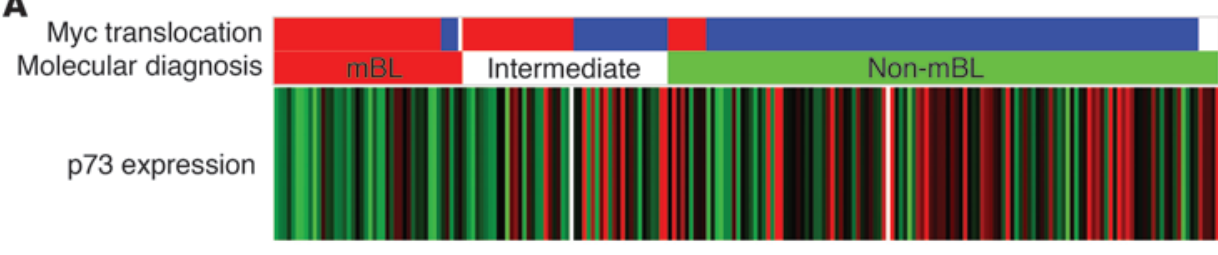

B

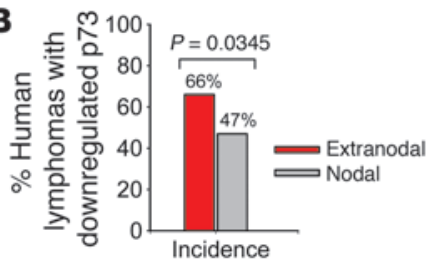

Figure 7

Correlation between p73 downregulation and dissemination in mature aggressive human lymphomas. (A) Expression of the TP73 gene in 221 human cases of mature aggressive B lymphomas analyzed in ref. 40. Cases with p73 downregulation (green), upregulation (red), or no change (black) compared with the average p73 expression of all 221 cases are indicated. White, not available. The middle bar indicates classification by molecular diagnosis according to ref. 40; molecular Burkitt lymphoma (red); intermediate (white); non-mBL (green). The top bar indicates the presence or absence of Myc translocation; positive (red); negative (blue); not available (white). (B) Incidence of human extranodal and nodal lymphomas with downregulated p73. (C) Relative levels of $p 73$ mRNA expression in extranodal $(\mathrm{E} \times \mathrm{N})$ versus nodal $(\mathrm{N})$ human lymphomas. Box plot analyses based on all ExN $(n=65)$ and $\mathrm{N}(n=66)$ lymphomas (left), or $\mathrm{E} \times \mathrm{N}(n=43)$ and $\mathrm{N}(n=31)$ lymphomas (right) classified as exhibiting greater than 2-fold downregulation of p73 with respect to the entire 221 case cohort. The horizontal line within the boxes indicates the median expression level, with the lower and upper box representing the 25th and 75th percentile, respectively. Whiskers demarcate the 10th and 90th percentile.

whose contribution lies mainly in preventing tumor dissemination and extranodal growth. Thus, in this system, p73 functions as a tumor modifier and not as classic tumor suppressor and loss of p73 expression is likely to be a late event in the course of B lymphoma evolution. The fact that $\mathrm{p} 73$-null mice are not cancer prone but develop tumors only when crossed into $\mathrm{E} \mu$-myc mice further argues that at least in this oncogenic context, $\mathrm{p} 73$ is not a primary tumor suppressor, and its deficiency would likely come into effect when B lymphomas are established. On the other hand, our data raise the possibility that in nascent tumor cells, oncogenic signals render p53 partly dependent on p73 function. In this respect, the absence of p53 mutations in p73-null Eu-myc tumors is somewhat surprising but not unprecedented. Loss-of-function mutations in Arf, ATM, Bim, or Bax, or overexpression of $\mathrm{Bcl} 2$ also cooperate with Myc and partly alleviate the pressure to inactivate p53 during lymphomagenesis $(34,45-48)$. As such, it will be important to delineate how specific oncogenic factors might influence the functional interactions between p53 and p73.

Human lymphoid malignancies are predominantly B cell in origin. They mainly belong to the NHL group, of which Burkitt lymphoma and DLBCL are important subgroups, and often involve chromosomal translocations among protooncogenes such as c-Myc, $\mathrm{Bcl} 1, \mathrm{Bcl} 2$, and $\mathrm{Bcl} 6$ and the immunoglobulin or other active loci (20). The proliferation and dissemination are equally important for lymphoma prognosis (39). Thus, in the International Prognostic Index for aggressive NHL, the number of extranodal sites is one of 4 prognostic variables (44). However, the molecular biology of lymphoma dissemination is incompletely understood and so far mainly based on clinical observations. Up until now, an important role in dissemination has been established for cell adhesion molecules (e.g., L-selectin and integrins), chemokine receptors, and chemokine ligands, which are also known to be involved in lymphocyte homing programs $(39,49-51)$. We show here in a genetically defined mouse model that p73 loss promotes extralymphatic dissemination of Myc-driven lymphoma and alters the transcriptional signature of the malignant $\mathrm{B}$ cells, including cell-surface-associated adhesion molecules, chemokine receptors, their ligands, and cluster of differentiation antigens. We find a parallel situation in a well-characterized large cohort of human mature aggressive B lymphomas. In particular, p73 expression was downregulated in $82 \%$ of human Burkitt lymphomas and $49 \%$ of Burkitt-like and DLBCL lymphomas. Most interestingly, these human lymphomas show a statistically significant correlation between incidence and degree of $\mathrm{p} 73$ downregulation and extranodal dissemination status. Moreover, deregulated genes that are shared between disseminating mouse and human B lymphomas can be identified. The prognostic value of $\mathrm{p} 73$ inactivation has been established in ALL, where p73 gene methylation was found in $21 \%$ of newly diagnosed ALL patients and correlated with unfavorable outcome (19). Unfavorable prognosis upon p73 loss was also confirmed by another independent study that used $251 \mathrm{ALL}$ patients (19). The prognostic value of p73 inactivation in human NHL has been speculated upon, but no clinical outcome data are available yet (reviewed in ref. 19). Our data suggest a hitherto unknown pathogenetic role of $\mathrm{p} 73$ as a lymphoma modifier, favoring dissemination. As such, p73 might be a putative biomarker for human B lymphoma dissemination, a notion that can now be tested in clinicopathologic correlation studies.

\section{Methods}

Mice. All animal studies were approved by the Institutional Animal Care and Use Committee at Stony Brook University. The study was littermate controlled and performed in a defined way (see below). Trp73-knockout mice (gift from F. Mckeon, Harvard Medical School, Boston, Massachusetts, USA; ref. 12) were maintained on the $129 \mathrm{~Sv}$ background. $p 73^{+/-}$mice were interbred with $\mathrm{C} 57 \mathrm{BL} / 6 \mathrm{E} \mu$-myc mice (Jackson Laboratory) to obtain the F1 generation of $\mathrm{E} \mu$-myc $p 73^{+/-}$transgenic animals. These were interbred with $p 73^{+/-}$mice to obtain the $\mathrm{F} 2$ generation $\mathrm{E} \mu$-myc $p 73^{+/+}, p 73^{+/-}$, and $p 73^{-/-}$transgenic animals $(129 \times \mathrm{B} 6 ; 75: 25) \cdot p 53^{+/} p 73^{+/-}$double-heterozygous mice were derived by crossing $p 73^{+--}$with $p 53^{-/-}$mice (Trp53tm1Tyj on the $129 \mathrm{~Sv}$ background, Jackson Laboratory). $p 53^{-/-} p 73^{+/-}$mice were derived from crosses between the double-heterozygous animals. $p 53^{-/} p 73^{-/-}$mice were derived from crosses between $p 53^{+/-} p 73^{+/-}$mice or $p 53^{+/-} p 73^{+/-}$with $p 53^{-/-} p 73^{+/-}$mice. $p 73^{+--}$Eu-myc transgenic mice $(129 \times \mathrm{B} 6)$ were crossed with $p 53^{-/-} p 73^{+--}$mice $(129 \mathrm{~Sv})$ to obtain the F1 generations of E $\mu$-myc $p 53^{+/-}, p 53^{+/-} p 73^{+/-}$, and $p 53^{+/-}$ $p 73^{-/-}$transgenic animals $(129 \times \mathrm{B} 6 ; 75: 25)$. Genotypes were verified by PCR amplifications specific for the corresponding WT and mutant alleles. All 
Table 3

Shared up- and downregulated genes in mouse and human lymphomas

\begin{tabular}{|c|c|}
\hline Gene symb & Gene name \\
\hline \multicolumn{2}{|c|}{ Shared downregulated genes in disseminated mouse lymphomas } \\
\hline \multicolumn{2}{|l|}{ Cell surface } \\
\hline Ryk & Receptor-like tyrosine kinase \\
\hline Thbd & Thrombomodulin \\
\hline Ankrd6 & Ankyrin repeat domain 6 \\
\hline St7 & Suppression of tumorigenicity 7 \\
\hline Itm2a & Integral membrane protein $2 \mathrm{~A}$ \\
\hline Ssfa2 & Sperm-specific antigen 2 \\
\hline Col18a1 & Procollagen, type XVIII, alpha 1 \\
\hline St3gal5 & ST3 beta-galactoside alpha-2,3-sialyltransferase 5 \\
\hline Slamf7 & SLAM family member 7 \\
\hline \multicolumn{2}{|l|}{ Other } \\
\hline Anxa9 & Annexin A9 \\
\hline Mtmr3 & Myotubularin related protein 3 \\
\hline Gfi1 & Growth factor independent 1 \\
\hline Aco1 & Aconitase 1 \\
\hline Asah1 & $\mathrm{N}$-acylsphingosine amidohydrolase 1 \\
\hline Gna12 & Guanine nucleotide binding protein, alpha 12 \\
\hline Rragd & Ras-related GTP binding D \\
\hline Arhgap24 & Rho GTPase activating protein 24 \\
\hline SIc39a6 & $\begin{array}{l}\text { Solute carrier family } 39 \text { (metal ion transporter), } \\
\text { member } 6\end{array}$ \\
\hline Dusp22 & Dual specificity phosphatase 22 \\
\hline Ptpla & $\begin{array}{l}\text { Protein tyrosine phosphatase-like (proline } \\
\text { instead of catalytic arginine), member }\end{array}$ \\
\hline Acs/1 & Acyl-CoA synthetase long-chain family member 1 \\
\hline Farp1 & $\begin{array}{c}\text { FERM, RhoGEF (Arhgef) and pleckstrin domain } \\
\text { protein } 1\end{array}$ \\
\hline Farp2 & FERM, RhoGEF and pleckstrin domain protein \\
\hline Arntl & Aryl hydrocarbon receptor nuclear translocator-like \\
\hline Acs/4 & $\begin{array}{c}\text { Acyl-CoA synthetase long-chain family member } 4 \text {, } \\
\text { transcript variant } 1\end{array}$ \\
\hline Pcnx & Pecanex homolog (Drosophila) \\
\hline Aph1b & $\begin{array}{l}\text { Anterior pharynx defective } 1 \mathrm{~b} \text { homolog } \\
\text { (Caenorhabditis elegans) }\end{array}$ \\
\hline Tle1 & $\begin{array}{l}\text { Transducin-like enhancer of split } 1 \\
\text { homolog of Drosophila } E(\mathrm{spl})\end{array}$ \\
\hline Mgll & Monoglyceride lipase \\
\hline Freq & Frequenin homolog (Drosophila) \\
\hline Plk2 & Polo-like kinase 2 \\
\hline Rnf125 & Ring finger protein 125 \\
\hline Atp $1 b 1$ & ATPase, $\mathrm{Na}^{+} / \mathrm{K}^{+}$transporting, beta 1 polypeptide \\
\hline Gadd $45 g$ & Growth arrest and DNA-damage-inducible 45 gamma \\
\hline Tmod1 & Tropomodulin 1 \\
\hline \multicolumn{2}{|c|}{$\begin{array}{l}\text { Shared upregulated genes in disseminated mouse } \\
\text { and human lymphomas }\end{array}$} \\
\hline \multicolumn{2}{|l|}{ Cell Surface } \\
\hline$Z y x$ & Zyxin \\
\hline Ifitm3 & Interferon-induced transmembrane protein 3 \\
\hline Csf3r & Colony-stimulating factor 3 receptor (granulocyte) \\
\hline P2ry6 & Pyrimidinergic receptor P2Y, G-protein coupled, 6 \\
\hline Cybb & Cytochrome b-245, beta polypeptide \\
\hline \multicolumn{2}{|l|}{ Other } \\
\hline S100a11 & S100 calcium-binding protein A11 (calgizzarin) \\
\hline Cd63 & Cd63 antigen \\
\hline Ifi30 & Interferon gamma inducible protein 30 \\
\hline$H k 3$ & Hexokinase 3 \\
\hline
\end{tabular}

animals were genotyped twice, at the time of weaning and when sacrificed. Our experimental end point was defined in the following way: mice were monitored every day for palpable tumors. The maximum tumor size allowed did not exceed $1 \mathrm{~cm}^{3}$. Mice were also monitored for systemic signs of illness, apathy, breathing problems, precipitous weight loss, and limited ability to reach food or water. This was particularly obvious in $p 73^{-1-}$ E $\mu$-myc because they predominantly developed systemic disease rather than palpable tumors. Mice fulfilling any of these criteria were euthanized and subjected to careful necropsy examination. Tumors were harvested and processed for histological examination. For in vivo dissemination assays, 1 million freshly isolated lymphoma cells was injected into the tail veins of CD-1 athymic nude mice (Taconic Farms). After 25 days, reconstituted mice were subject to autopsy; tumors were weighed and tissues processed histologically.

Flow cytometry. Fresh lymphoid tissue samples were examined by flow cytometry with antibodies to CD19, CD25, CD43, CD44, B220 (CD45R), IgM, IgD, c-Kit, and Sca1 (BD Pharmingen and eBioscience). For cell-cycle analysis, lymphoid cells were fixed in $70 \%$ ethanol, stained with propidium iodide, and analyzed using FACSCalibur (BD) with CellQuest software. Annexin V (Roche) staining was performed to measure apoptosis.

Expression analysis. Semiquantitative and quantitative real-time RT-PCR were performed using whole-cell RNAs prepared from primary lymphoid cells or tumors. The sequences of primers are listed in Supplemental Table 2. For protein analysis, aliquots of whole-cell lysates (50-80 $\mu \mathrm{g}$ of protein) were separated on SDS-acrylamide gels and blotted onto a Protran BA85 nitrocellulose membrane (Schleicher \& Schüell). They were then incubated with antibodies specific for p53 (FL-393), Mdm2 (SMP14, both from Santa Cruz Biotechnology Inc.); p19ARF (ab80, Novus Biologicals); and MAPK (3A7; Cell Signaling). Comparative genomic hybridization (CGH analysis) and Spectral karyotyping (SKY) were performed at the Roswell Park Cancer Institute (Buffalo, New York, USA).

Expression microarray. Only tumors that showed at least 95\% B cell enrichment by FACS analysis were selected. Total RNA was extracted from representative tumors of 3-month-old E $\mu$-myc $p 73^{+/+}$and E $\mu$-myc $p 73^{-/-}$mice ( 3 animals per genotype) using the RNeasy Mini Kit (QIAGEN). The integrity of RNA was validated with Bioanalyzer 2100 QC (all samples RIN > 7.0). One-color hybridizations of labeled cRNAs (2 technical replicas) were performed against the mouse Agilent 44K/60-mer oligonucleotide microarray according to the manufacturer's instructions (Empire Genomics LLC). Normalized, differentially expressed genes were defined as greater than 2 -fold change and $P<0.05$ (Student's $t$ test).

Statistics. Statistical analyses were performed using the following tests: a single-factor ANOVA at a 95\% level of confidence (Figure 2B and Figure $4 \mathrm{~B})$; the log-rank test (Figure 3A); Fisher's exact test, 2-tailed (Figure 4E and Figure 7B); and Student's $t$ test, 2 -tailed (Figure 7C). $P \leq 0.05$ was considered statistically significant.

\section{Acknowledgments}

This work was supported by grants from the National Cancer Institute, the Deutsche Krebshilfe, the Carol Baldwin Foundation, and the Lymphoma Research Foundation (to A. Nemajerova). The authors thank the Molecular Mechanisms of Malignant Lymphoma Consortium funded by Deutsche Krebshilfe, University of Göttingen.

Received for publication October 9, 2009, and accepted in revised form March 24, 2010.

Address correspondence to: Ute M. Moll, Department of Pathology, Stony Brook University, Stony Brook, New York 11794, USA. Phone: 631.444.2459; Fax: 631.444.3424; E-mail: umoll@ notes.cc.sunysb.edu. 
1. Jost CA, Marin MC, Kaelin WG Jr. p73 is a simian [correction of human] p53-related protein that can induce apoptosis. Nature. 1997;389(6647):191-194.

2. Kaghad M, et al. Monoallelically expressed gene related to $\mathrm{p} 53$ at $1 \mathrm{p} 36$, a region frequently deleted in neuroblastoma and other human cancers. Cell. 1997;90(4):809-819.

3. Zhu J, Jiang J, Zhou W, Chen X. The potential tumor suppressor $\mathrm{p} 73$ differentially regulates cellular $\mathrm{p} 53$ target genes. Cancer Res. 1998;58(22):5061-5065.

4. Fang L, Lee SW, Aaronson SA. Comparative analysis of $\mathrm{p} 73$ and $\mathrm{p} 53$ regulation and effector functions. J Cell Biol. 1999;147(4):823-830.

5. Irwin $M$, et al. Role for the p53 homologue p73 in E2F-1-induced apoptosis. Nature. 2000; 407(6804):645-648

6. Griesmann H, Schlereth K, Krause M, Samans B, Stiewe T. p53 and p73 in suppression of Myc-driven lymphomagenesis. Int J Cancer. 2009;124(2):502-506.

7. Scian MJ, et al. Wild-type p53 and p73 negatively regulate expression of proliferation related genes. Oncogene. 2008;27(18):2583-2593

8. Petrenko O, Zaika A, Moll UM. deltaNp73 facilitates cell immortalization and cooperates with oncogenic Ras in cellular transformation in vivo. Mol Cell Biol. 2003;23(16):5540-5555.

9. Moll UM, Slade N. p63 and p73: roles in development and tumor formation. Mol Cancer Res. 2004;2(7):371-386.

10. Melino G, De Laurenzi V, Vousden KH. p73: Friend or foe in tumorigenesis. Nat Rev Cancer. 2002; 2(8):605-615.

11. Deyoung MP, Ellisen LW. p63 and p73 in human cancer: defining the network. Oncogene. 2007; 26(36):5169-5183.

12. Yang A, et al. p73-deficient mice have neurological, pheromonal and inflammatory defects but lack spontaneous tumours. Nature. 2000;404(6773):99-103.

13. Flores ER, et al. Tumor predisposition in mice mutant for p63 and p73: evidence for broader tumor suppressor functions for the p53 family. Cancer Cell. 2005;7(4):363-373.

14. Perez-Losada J, Wu D, DelRosario R, Balmain A, Mao JH. p63 and p73 do not contribute to p53mediated lymphoma suppressor activity in vivo. Oncogene. 2005;24(35):5521-5524.

15. Tomasini $\mathrm{R}$, et al. TAp73 knockout shows genomic instability with infertility and tumor suppressor functions. Genes Dev. 2008;22(19):2677-2691.

16. Martinez-Delgado B, et al. Frequent inactivation of the p73 gene by abnormal methylation or $\mathrm{LOH}$ in non-Hodgkin's lymphomas. Int J Cancer. 2002; 102(1):15-19.

17. Corn PG, et al. Transcriptional silencing of the $\mathrm{p} 73$ gene in acute lymphoblastic leukemia and Burkitt's lymphoma is associated with $5^{\prime} \mathrm{CPG}$ island methylation. Cancer Res. 1999;59(14):3352-3356.

18. Kawano S, et al. Loss of p73 gene expression in leukemias/lymphomas due to hypermethylation. Blood. 1999;94(3):1113-1120.
19. Pluta A, Nyman U, Joseph B, Robak T, Zhivotovsky $\mathrm{B}$, Smolewski P. The role of p73 in hematological malignancies. Leukemia. 2006;20(5):757-766.

20. Kuppers R. Mechanisms of B-cell lymphoma pathogenesis. Nat Rev Cancer. 2005;5(4):251-262.

21. Siu LL, Chan JK, Wong KF, Kwong YL. Specific patterns of gene methylation in natural killer cell lymphomas: p73 is consistently involved. Am J Pathol. 2002;160(1):59-66.

22. Adams JM, et al. The c-myc oncogene driven by immunoglobulin enhancers induces lymphoid malignancy in transgenic mice. Nature. 1985;318(6046):533-538.

23. Adams JM, Cory S. Transgenic models of tumor development. Science. 1991;254(5035):1161-1167.

24. Lowe SW, Sherr CJ. Tumor suppression by Ink4aArf: progress and puzzles. Curr Opin Genet Dev. 2003;13(1):77-83.

25. Zaika A, Irwin M, Sansome C, Moll UM. Oncogenes induce and activate endogenous $\mathrm{p} 73$ protein. J Biol Chem. 2001;276(14):11310-11316.

26. Talos F, Nemajerova A, Flores ER, Petrenko O, Moll UM. p73 Suppresses polyploidy and aneuploidy in the absence of functional p53. Mol Cell. 2007;27(4):647-659.

27. Langdon WY, Harris AW, Cory S, Adams JM. The c-myc oncogene perturbs B lymphocyte development in E-mu-myc transgenic mice. Cell. 1986;47(1):11-18.

28. Hsu B, Marin MC, el-Naggar AK, Stephens LC, Brisbay S, McDonnell TJ. Evidence that c-myc mediated apoptosis does not require wild-type p53 during lymphomagenesis. Oncogene. 1995;11(1):175-179.

29. Schmitt CA, McCurrach ME, de Stanchina E, WallaceBrodeur RR, Lowe SW. INK4a/ARF mutations accelerate lymphomagenesis and promote chemoresistance by disabling p53. Genes Dev. 1999;13(20):2670-2677.

30. Pasqualucci L, Kitaura Y, Gu H, Dalla-Favera R. PKA-mediated phosphorylation regulates the function of activation-induced deaminase (AID) in B cells. Proc Natl Acad Sci U S A. 2006;103(2):395-400.

31. Mahowald GK, Baron JM, Sleckman BP. Collateral damage from antigen receptor gene diversification. Cell. 2008;135(6):1009-1012.

32. De Paepe P, De Wolf-Peeters C. Diffuse large B-cell lymphoma: a heterogeneous group of non-Hodgkin lymphomas comprising several distinct clinicopathological entities. Lenkemia. 2007;21(1):37-43.

33. Watanabe $\mathrm{K}$, et al. Physical interaction of $\mathrm{p} 73$ with c-Myc and MM1, a c-Myc-binding protein, and modulation of the p73 function. J Biol Chem. 2002 277(17):15113-15123.

34. Eischen CM, Weber JD, Roussel MF, Sherr CJ, Cleveland JL. Disruption of the ARF-Mdm2-p53 tumor suppressor pathway in Myc-induced lymphomagenesis. Genes Dev. 1999;13(20):2658-2669.

35. Bertwistle D, Sherr CJ. Regulation of the Arf tumor suppressor in Emicro-Myc transgenic mice: longitudinal study of Myc-induced lymphomagenesis. Blood. 2007;109(2):792-794.

36. Vikhanskaya F, Marchini S, Marabese M, Galliera $\mathrm{E}$, Broggini M. P73a overexpression is associated with resistance to treatment with DNA-damaging agents in a human ovarian cancer cell line. Cancer Res. 2001;61(3):935-938.

37. Wei CL, et al. A global map of p53 transcriptionfactor binding sites in the human genome. Cell. 2006;124(1):207-219.

38. Fontemaggi $\mathrm{G}$, et al. Identification of direct $\mathrm{p} 73$ target genes combining DNA microarray and chromatin immunoprecipitation analyses. J Biol Chem. 2002; 277(45):43359-43368.

39. Pals ST, de Gorter DJ, Spaargaren M. Lymphoma dissemination: the other face of lymphocyte homing. Blood. 2007;110(9):3102-3111.

40. Hummel M, et al. A biologic definition of Burkitt's lymphoma from transcriptional and genomic profiling. NEngl J Med. 2006;354(23):2419-2430.

41. Tanaka SS, Yamaguchi YL, Tsoi B, Lickert H, Tam $\mathrm{PP}$. IFITM/Mil/fragilis family proteins IFITM1 and IFITM3 play distinct roles in mouse primordial germ cell homing and repulsion. Dev Cell. 2005; 9(6):745-756

42. Spinardi L, Marchisio PC. Podosomes as smart regulators of cellular adhesion. Eur J Cell Biol. 2006; 85(3-4):191-194.

43. Mori S, et al. Utilization of pathway signatures to reveal distinct types of B lymphoma in the Emicromyc model and human diffuse large B-cell lymphoma. Cancer Res. 2008;68(20):8525-8534.

44. [No authors listed]. A predictive model for aggressive non-Hodgkin's lymphoma. The International Non-Hodgkin's Lymphoma Prognostic Factors Project. NEngl J Med. 1993;329(14):987-994.

45. Eischen CM, Roussel MF, Korsmeyer SJ, Cleveland JL. Bax loss impairs Myc-induced apoptosis and circumvents the selection of p53 mutations during Myc-mediated lymphomagenesis. Mol Cell Biol. 2001;21(22):7653-7662.

46. Egle A, Harris AW, Bouillet P, Cory S. Bim is a suppressor of Myc-induced mouse B cell leukemia. Proc Natl Acad Sci U S A. 2004;101(16):6164-6169.

47. Hemann MT, et al. Evasion of the p53 tumour surveillance network by tumour-derived MYC mutants. Nature. 2005;436(7052):807-811.

48. Maclean KH, Kastan MB, Cleveland JL. Atm deficiency affects both apoptosis and proliferation to augment Myc-induced lymphomagenesis. Mol Cancer Res. 2007;5(7):705-711.

49. Deutsch AJ, et al. Distinct signatures of B-cell homeostatic and activation-dependent chemokine receptors in the development and progression of extragastric MALT lymphomas. J Pathol. 2008;215(4):431-444.

50. Belanger SD, St-Pierre Y. Role of selectins in the triggering, growth, and dissemination of T-lymphoma cells: implication of L-selectin in the growth of thymic lymphoma. Blood. 2005;105(12):4800-4806.

51. Kurtova AV, Tamayo AT, Ford RJ, Burger JA. Mantle cell lymphoma cells express high levels of CXCR4, CXCR5, and VLA-4 (CD49d): importance for interactions with the stromal microenvironment and specific targeting. Blood. 2009;113(19):4604-4613. 